\title{
Vigencia del abordaje psicoanalítico del cuerpo
}

\section{Relevance of the psychoanalytic approach of the body}

\section{Silvina Garo}

\section{RESUMEN:}

Este artículo propone un recorrido sobre el modo en que Freud y Lacan abordan la cuestión del cuerpo a partir del descubrimiento de lo inconsciente para poner en primer plano la incidencia que dicho descubrimiento produce, en tanto modifica radicalmente la idea de cuerpo pensado desde la racionalidad cartesiana. A partir de la enseñanza de Jacques Lacan en su abordaje desde los tres registros, se desarrolla el modo en que el cuerpo puede ser pensado desde lo Simbólico, lo imaginario y lo real. Así es que puede establecerse un contrapunto tanto con la concepción biologicista como con el abordaje contemporáneo de la modernidad tardía o posmodernidad. El artículo permite echar luz sobre dos concepciones antagónicas del cuerpo, vigentes y puestas en tensión, donde es posible verificar tanto la vigencia del abordaje psicoanalítico como la incidencia política de su discurso en nuestra sociedad, tomando como referente el debate sobre la ley del aborto discutida en el Congreso de la Nación.

\section{Palabras clave:}

Cuerpo - inconsciente - tres registros biopolítica - psicoanálisis

\section{SUMMARY:}

This paper seeks to examine the way in which Freud and Lacan address the body issue from the discovery of the unconscious so as to foreground the influence exerted by such discovery, in that it alters dramatically the notion of the body conceived from Cartesian rationality. Following Jacques Lacan's teachings on his approach of the three orders, the way the body can be thought of from the Symbolic, the Imaginary and the Real is developed. Thus a counterpoint can be established both with the biologic concept and the contemporary approach linked with late Modernity or post modernity. This article casts light upon two opposing notions of the body, valid and opposed, where it is possible to verify both the validity of the psychoanalytic approach and the political impact of its discourse on our society, taking the debate on decriminalisation of abortion, discussed in Congress, as a point of reference.

\section{WORD PAD:}

Body - unconscious - three orders biopolitics - psychoanalysis 

Elegí nombrar este artículo "Vigencia del abordaje psicoanalítico del cuerpo" y, poner el acento fundamentalmente en lo que creo hoy nos importa, esto es: la vigencia y por qué no, la importancia actual del abordaje que propone el psicoanálisis del cuerpo.

La propuesta se centra en ubicar lo específico del abordaje psicoanalítico para luego situar dos ángulos con los que el psicoanálisis ofrece su contrapunto: una es la concepción biomédica y otra el pensamiento contemporáneo sobre el cuerpo. A medida que fui armando el texto, caigo en la cuenta de que ese contrapunto es constitutivo de la posición del psicoanálisis, que el mismo nace y se sostiene en ese contrapunto. Entonces hablar de psicoanálisis o de la clínica psicoanalítica implica conversar, discutir y también confrontar con esos discursos; inevitablemente es plantear las diferencias. No es sin la instalación del discurso de la ciencia que puede nacer como aquello que viene a cuestionar y a poner en entredicho dicha concepción. Quienes trabajan en centros de salud, hospitales, centros de día, etc., están quizás cotidianamente confrontados con esta cuestión pero no debemos olvidar que, como se trata de discursos y de posiciones discursivas, éstas atraviesan y trascienden el espacio que concierne a las prácticas médicas.

\section{Del CUERPo QUE HABLA AL CUERPO QUE GOZA}

Comienzo recordando aquí que para el psicoanálisis el cuerpo que importa es el cuerpo erógeno, ese cuerpo tallado por la pulsión, es decir por la sexualidad perversa polimorfa en primera instancia pero de la que sabemos no hay instancias madurativas ni superadoras sino que, tomados en esa sexualidad perversa polimorfa, estamos concernido por la diferencia de los sexos.

Sabemos que el primer paso lo dio Freud haciendo hablar al cuerpo de la histérica, o mejor dicho, escuchando su decir puesto en el cuerpo como síntoma. Freud pone al cuerpo en relación con un decir que se manifiesta no en palabras sino en síntoma y entonces de lo que se trata es de un desciframiento de esa inscripción jeroglífica.

Allí está la clave: un mensaje cifrado, un decir jeroglífico que llama a descifrar, es decir a interpretar. Primero Freud lo descubre en el cuerpo de la histérica pero luego lo va a encontrar en otras formaciones extrañas: sueños, actos fallidos, olvidos. Todos ellos puestos a descifrar a partir de una escucha que los interroga. Como sabemos, se trata del descubrimiento del inconsciente...

¿Pero el descubrimiento del inconsciente no modifica radicalmente la idea de cuerpo?

Al menos del cuerpo pensado orgánicamente. En sus albores Freud nos dice que la idea de brazo que posee una histérica no coincide exactamente con el de la anatomía, lo que hace que una parálisis histérica venga a cuestionar los saberes formalizados en el discurso médico. (Freud, 1893 , p. 208). Freud produce allí un giro, una escansión y por qué no un acto, el de producir un discurso que subvierte lo que para la ciencia era escamoteable, desechable, o al menos no tenido en cuenta: la relación del sujeto con los objetos de goce.

El descubrimiento de otro cuerpo que no responde al saber médico sino que responde a las leyes del inconsciente, tremen- 
do giro subversivo el que produce Freud. Entonces a partir de este descubrimiento tan capital para nosotros, el abordaje psicoanalítico del cuerpo involucra, concierne a cómo irremediablemente ese cuerpo, no sólo queda afectado por lo inconsciente sino que hablar de cuerpo en psicoanálisis es pensar la manera en que cada uno se las ha arreglado para tener un cuerpo o no.

Encontramos respuestas colectivas y variables históricas de portar un cuerpo pero sobretodo está la manera en que cada uno y cada una hace con ella a través de sus respuestas sintomáticas. Esa forma singular de habitar el cuerpo marcado por los avatares de la historia personal y subjetiva es fundamentalmente la marca, cómo el cuerpo fue marcado en su encuentro con el Otro.

Para el psicoanálisis el cuerpo no es un apriori que se constata en el momento de nacimiento. Es una posibilidad, también una apuesta, un esperable a partir de que el cachorro humano (infant, que quiere decir que no posee la palabra) se transforma por la inmixión del lenguaje, para advenir parletre, parlanteser. A partir de ese incorporal "que es el lenguaje, que en tanto se incorpora, da cuerpo" (Lacan, 1977 p.431). Este cuerpo simbólico, anterior al cuerpo como imagen, es producto de esa incorporación del lenguaje que van produciendo las marcas significantes.

Primera muerte nos dice Lacan, pérdida de la pura vida propia de los animales, del contacto con la Naturaleza y los ciclos vitales, que hace a la caída el soma como organismo viviente para transformarse en cuerpo pulsional.

Esta es la primera apuesta a tener un cuerpo en el registro de lo humano: estar inmersos en el lenguaje. Pero eso no nos garantiza hasta este momento que se pueda homologar con el yo, es decir con esa superficie, con sus bordes y sus límites, que se vaya modelando, tallando por la pulsión hasta la conformación de una imagen unificada.

Será necesario entonces una segunda instancia. Hace falta contar con esa temprana ilusión de completud y de unicidad producida por ese pasaje por la cobertura imaginaria que permite a alguien nombrarse como yo y constituir esa alteridad necesaria para poder tomar la palabra y diferenciarse. La alienación en la imagen especular es, entonces, estructurante; produce la inscripción de las palabras y los significantes en el cuerpo; cuerpo que encarna para siempre esos significantes: los de las demandas y del deseo del Otro.

Hablar de cuerpo como Uno, como unidad es la resultante entonces, de un complejo proceso que no siempre llega a buen puerto, como testimonia su carencia la clínica del autismo. A diferencia de la esquizofrenia que evidencia su fragilidad: Cuando un insomnio es más que una noche en vela porque un real resiste su tramitación, cuando el no poder dormir amenaza a la fragmentación o a la invasión de voces que lo hablan.

Cuerpo entonces es más que ese conjunto de órganos que nos invita a considerar la racionalidad cartesiana con la metáfora del cuerpo como máquina, más exactamente como un reloj; el cuerpo es esa imagen que se forja de sí como resultado del encuentro con el otro, lo que nos permite pensarnos y pensar al otro como semejante a la vez que deja afuera a $\mathrm{La}$ Cosa, Das Ding en el territorio de lo extranjero y por lo tanto extraño y hostil. No podemos pensarnos, hablar, tomar la palabra sin un cuerpo como imagen, como "proyección de una superficie", nos dice 
Freud en el "Yo y el ello". (Freud, 1923, p.27) Lo remarco porque entre la adquisición, la incorporación del lenguaje y la posibilidad de tomar la palabra y apostar a un decir propio, que implica decir más de lo que se dice, no es sin esa experiencia de constitución del cuerpo.

El descubrimiento de lo inconsciente afecta para siempre la concepción dual de cuerpo y alma. Es desde allí que Freud dirigió su pregunta a los filósofos en una carta dirigida a Grodeck "¿en qué medida los teóricos del cuerpo se han dado la tarea de repensar las relaciones entre cuerpo y alma teniendo en cuenta el descubrimiento de lo inconsciente?" Y remata diciendo: "Quizás sea lo inconsciente el eslabón perdido entre lo psíquico y lo somático..." (Grodeck, 1977, p.44) Nos habla de los "procesos psíquicos inconscientes" y plantea su "fuerte e intensa influencia plástica sobre el cuerpo". Cuando habla de una influencia plástica intensa (Freud, 1915, p.184, nota6) sobre el cuerpo de los procesos inconscientes, hay que entender que no se refiere a una influencia masiva y mágica sobre el cuerpo sino de una influencia susceptible de adquirir diversas formas. Esta posibilidad de adquirir diversas formas nos ubica en el corazón de nuestra clínica.

Tomo una hipótesis que plantea Roberto Mazzuca en uno de sus libros; hablando de la sexualidad masculina, él plantea el lugar que ocupan los objetos parciales en la conformación del cuerpo y su valor erótico decisivo, pero también va a hablar de qué otros objetos forman parte del cuerpo: "no se trata necesariamente de un objeto material. Puede ser una prenda pero también un rasgo corporal o rasgo gestual que como condición erótica del objeto pueden ser considerados partes del cuerpo" (Mazzuca, 2003, p.78). Recordé entonces a Barthes y su libro "Fragmento de un discurso amoroso":

Encuentro en mi vida millones de cuerpos; de esos millones puedo desear centenares; pero de esos centenares, no amo sino uno. El otro del que estoy enamorado me designa la especificidad de mi deseo.... Han sido necesarias muchas casualidades, muchas coincidencias sorprendentes ( $\mathrm{y}$ tal vez muchas búsquedas), para que encuentre la Imagen que, entre mil, conviene a mi deseo. Hay allí un gran enigma del que jamás sabré la clave: ¿Por qué deseo a Tal? ¿Por qué lo deseo perdurablemente, lánguidamente? ¿Es todo él lo que deseo (una silueta, una forma, un aire) $\dot{\iota} \mathrm{O}$ no es solo mas que una parte de su cuerpo? Y en ese caso, ¿qué es lo que en ese cuerpo amado tiene vocación de fetiche para mi? ¿Qué porción tal vez increíblemente tenue, qué accidente? ¿El corte de una uña, un diente un poco rajado, un mechón, una manera de mover los dedos al hablar, al fumar? De todos esos pliegues del cuerpo tengo ganas de decir que son adorables. Adorable quiere decir: éste es mi deseo en tanto que es único: es eso! es exactamente eso lo que yo amo"(Barthes, 1971, p.22 )

El fetichismo es una de esas formas que más pone sobre el tapete lo que el cuerpo es: Acaso aquel brillo en la nariz que tan magistralmente nos describiera Freud no es parte esencial e indiscutida del cuerpo? o esas medias de seda elegidas con tanto esmero, no forman parte esencial del cuerpo como condición necesaria del erotismo y posibilidad de asumir una posición sexuada del lado en que algunos hombre, como sabemos, reniegan de la castración? 
El travesti requiere de sus vestimentas y sus velos para asumir su cuerpo y proclamarse mujer. Los gestos, los modos de mover la cabeza, como diría Barthes ese diente torcido,.. y por qué no también las dentaduras postizas y todos aquellos postizos como los lentes o las pestañas... y los objetos tecnológicos que ensanchan la potencia y son prolongaciones de las propias capacidades corporales. Entonces: ¿el cuerpo dónde termina? en la piel? ¿en el vestido?, ¿hasta dónde se reduce o se extiende si no es sólo una superficie sino "proyección de una superficie"?

¿Qué decir de la experiencia trans en la que alguien proclama ser una mujer en el cuerpo de un hombre? En el empuje a las constantes cirugías y transformaciones del cuerpo, a veces llegando al límite, al riesgo de perder la vida... ¿Dónde está instalada la sexuación de un sujeto? ¿La sexuación se instalada en el cuerpo? O es esa la confusión que denuncia Lacan en $\mathrm{Ou}$ pire como un "error común", el que confunde el órgano peniano con la función fálica. Justamente por estar desprovisto de la función fálica intenta corregir el "error" mediante la cirugía, interviniendo en el cuerpo. (Lacan, 1971, p. 17)

Si bien Lacan siguiendo el surco forjado por Freud, remite a la dimensión imaginaria del cuerpo, avanza en su enseñanza: al inicio descubre la textura de imagen que tiene el cuerpo; el cuerpo es de la estofa de lo imaginario desde su teoría del estadio del espejo. Es muchos años después, a partir del esquema óptico el que le permite encontrarse con lo real del cuerpo o con el cuerpo real: con aquello que se esconde dentro de la caja, que es ese inaccesible, ese -Fi no especularizable que necesariamente debe faltar a la captura por la imagen pero que cuando no falta, angustia.
La angustia, eso que no engaña, única certeza de existir, es al mismo tiempo un acontecimiento del cuerpo, es justamente el instante del cuerpo en que pierde ésto que es de lo que veníamos hablando: que se pierde el control del uso funcional de los órganos, también del uso funcional de esa imagen que nos permite contar con una apariencia para el estar-en-el mundo. Momento en que vivimos la inminencia de la pérdida, pero que es también la posibilidad de advenimiento del síntoma. Si bien Lacan focaliza al "síntoma como acontecimiento en el cuerpo", (Lacan, 2001, p.595) creo que es la angustia mas que el síntoma, la que tiene prioritariamente ese estatuto de acontecimiento en el cuerpo.

La noción de "resto" marca el límite de la noción del cuerpo como texto o portador de un mensaje cifrado. Apunta al sujeto que, en su cuerpo y mediante su síntoma, da testimonio de la verdad de su modalidad de goce.

A partir de un momento de su enseñanza, Lacan propone que el gozar es gozar del cuerpo. Por supuesto que nosotros estamos advertidos que el goce no es el placer sino justamente en términos freudiano podemos decir que es el más allá del principio del placer. En 1967/68, Seminario El objeto en psicoanálisis, nos plantea:

El goce para nosotros no puede ser sino idéntico a toda presencia en el cuerpo. El goce no se aprehende, no se concibe sino por lo que el cuerpo es. La dimensión de goce me parece absolutamente coextensiva a la del cuerpo. (Lacan, $1967 / 68$ clase 15 )

¿Por qué es necesario entonces sostener ciertas nociones referidas al cuerpo, tal como se desprenden de la experiencia 
analítica a la hora de hacerle lugar en nuestra práctica? Porque sabemos que el psicoanálisis lejos de ser una normativa, que indique el modo correcto de gozar o el objeto conveniente a la relación, está concernido por una ética que intenta anudar la elección de goce con el lazo social.

El psicoanálisis no opera cerrando ninguna cuestión sino dando la palabra a aquellos que se prestan a la experiencia psicoanalítica para que emerja el cuerpo de cada sujeto, sacando a la luz los vericuetos imaginarios y, sobretodo, sacando a la luz los afectos y los efectos que le acarrea su anclaje en la civilización que lo ha producido. (Chapuis, 2013, p.130)

\section{ENFOQUE CONTEMPORÁNEO SOBRE EL} CUERPO: BIOPOLÍTICA Y PSICOANÁLISIS

Con esta cita, vuelvo a retomar una proposición que planteo al comienzo de este texto: hay respuestas colectivas y variables históricas de portar un cuerpo, lo que nos permite abrir la pregunta sobre lo que se podría denominar el enfoque contemporáneo sobre el cuerpo. Para este abordaje tomaré como referente un hecho histórico que aconteció hace pocos días en la Cámara de Diputados de la Nación respecto del debate sobre la ley de interrupción voluntaria del embarazo o ley del aborto legal, seguro y gratuito. Encuentro que en ese debate se juegan dos concepciones distintas, antagónicas del cuerpo que están sostenidas, por supuesto, en distintas posiciones políticas. Pero que fundamentalmente me sirven para verificar el postulado de mi trabajo: la vigencia del psicoanálisis o del discurso psicoanalítico que queda refleja- do en ese debate, en una de las posiciones. Es decir, confirma la incidencia política del psicoanálisis en las argumentaciones que inclinan la balanza a favor del aborto.

Para este abordaje me serviré del concepto foulcaultiano de biopolítica: "El control de la sociedad sobre los individuos no solo se efectúa sobre la conciencia o por la ideología, sino también en el cuerpo y con el cuerpo. Para la sociedad capitalista es lo bio-político lo que importa ante todo, lo biológico, lo somático, lo corporal." (Foucault, 2001, p.210)

Se trata entonces del disciplinamiento de los cuerpos, de esa configuración del Poder, la biopolítica, que organiza dispositivos de control y prácticas normativas sobre los cuerpos de los individuos a través de la higiene de la población, del control y la adaptación a los intereses del modelo capitalista, configurando las "subjetividades de la época" a su medida. Dentro de esos dispositivos de control, es posible ubicar las leyes que se legislan sobre la vida de las personas.

Podemos proponer que cada época consolida formaciones imaginarias que van adquiriendo consistencia y van configurando un pensamiento de lo que el cuerpo es, según las configuraciones históricas y socialmente cambiantes.

Tomo como referente para poder ubicar estas diferencias el discurso de la diputada Gabriela Cerutti quien mostró de un modo elocuente estas dos imágenes: Hay una concepción de cuerpo, del cuerpo de la mujer que es solidaria con la concepción biopolítica, con el disciplinamiento social de los cuerpos por médicos, educadores o en este caso sostenido por los poderes. Discursos sostenidos en el determinismo biologicista donde el ser humano se encuentra casi totalmente determinado 
por la maquinaria orgánica, hormonal y genética. Como lo expone Cerrutti, esta concepción se consolida en una imagen muy fuerte cristalizada en la idea del cuerpo de la mujer como receptáculo para la conservación de embriones, "asemejada a una heladera que conserve embriones" o en la comparación y homologación del cuerpo de la mujer con el cuerpo de "una perra que tiene que tener perritos para poder regalarlos". (Cerutti, 2018) Para no extendernos demasiado en la valoración de este pensamiento o estas imágenes, no es difícil afirmar de un modo contundente que estos pensamientos pertenecen al orden de los discursos totalizantes, aquellos que desconocen o niegan la intrínseca relación del Sujeto con aquellos objetos que conforman una modalidad de goce singular y que tienen como punto de partida la dimensión deseante, esto es, la dimensión de falta estructural, por estar constituidos en la esfera del lenguaje, cuestión que nos exiliada desde el vamos de la posibilidad de la mencionada comparación con "la perra y sus cachorritos".

Para estos discursos, cuyo representante paradigmático lo encontramos en las neurociencias, los trastornos, los problemas o las decisiones (como lo son los abortos que se practican como decisión y hecho incontrastable a pesar de la normativa y de los preceptos morales) son tomados como universales, es decir, despojados del sujeto que lo padece y de su sufrimiento singular para sustituir el relato singular de su historia por datos biológicos o culturales pero que fundamentalmente apuntan a la producción de subjetividad conformada como masa unificada, disciplinada y controlada, “mínima expresión de lo humano", parafraseando a Nora Merlín. (Merlin, 2017). Tal como apare- ce en algunos muros de Facebook: "Nada que discutir sobre el aborto, la mejor de las dos opciones es la de la legalización, porque la de la probibición obliga a una parte a vivir según las convicciones de la otra" (Del muro de Eva Lenczner, el destacado es mío)

En contraste y como contrapunto de esta concepción, nos encontramos con otra respuesta colectiva que nos habla de otras variables históricas. Es posible afirmar que la invención del psicoanálisis ha tenido una incidencia decisiva en la configuración de las nuevas imágenes contemporáneas sobre el cuerpo.

A mi entender, un capítulo preponderante lo ocupa el empuje de los movimientos feministas y de liberación sexual en el debate contemporáneo, "que desembocaron en importantes modificaciones jurídicas y políticas de las estructuras de parentesco, de los modelos de filiación y de la organización familiar” (Cevasco, 2010, p.13), modificaciones que se tradujeron en el matrimonio de parejas homosexuales o en la posibilidad de concebir o adoptar en parejas gays y que hoy ha llevado al centro de la discusión política el debate sobre el aborto. Ya Lacan, en El saber del psicoanalista nos habla de una verdadera subversión sexual producida en los últimos 50 años, nos dice (Lacan, 1971). Tal como no lo desconoció Lacan en su tiempo, no podemos desconocer ni negar la incidencia de estos movimientos y estas luchas sociales en la actualidad.

Hace tiempo ya que los psicoanalistas hemos podido cuestionar la proposición freudiana que sentencia a "la anatomía como destino". (Freud, 1912) También hemos podido verificar la existencia de otras salidas para la feminidad que no hacen de la maternidad, el único modo en 
que la niña conquista su hacerse mujer. Sabemos que hoy cuando se amplían las conquistas de derechos, también se amplían el universo de posibilidades en cuanto a la elección de objetos que vienen a sustituir la falta fálica, que no se reduce necesariamente en el deseo de hijo. Allí toman lugar otros objetos que hacen a la realización como mujer del lado "todo, lugar posible tanto para hombres como para mujeres en el caso de estar atravesados por la significación fálica.

En el Congreso se escucharon diversos alegatos que tomaban como argumento principal el derecho a decidir sobre su propio cuerpo de aquellas mujeres que deciden abortar. La reivindicación que se hace del cuerpo, hay también que pensarla como producto de las nuevas configuraciones históricas donde justamente el cuerpo está a la orden del día!

En la escena posmoderna o modernidad tardía, según como se la denomine, aparecen toda una serie de prácticas que tienen que ver con las "técnicas corporales". Asistimos a un narcisismo de la imagen que toma al cuerpo, al retorno de prácticas ancestrales como el yoga o la meditación, los cuidados constantes del cuerpo: gimnasios, estéticas, cirugías. El cuerpo elevado a la dignidad de bien supremo!, lo que nos alerta sobre la posibilidad de quedar tomados en una lógica superyoica, bajo los imperativos de juventud y belle$\mathrm{za}$, sometidos a regímenes y privaciones a condición de llegar a hacer consistir esos ideales narcisistas, al servicio del discurso capitalista y la fetichización del cuerpo como mercancía.

En este nuevo contexto donde el cuerpo lejos de esconderse, de taparse, ha subido a escena, el discurso de la diputada tiene el enorme valor de poner sobre el tapete la dimensión que verdaderamente importa: la dimensión deseante como condición necesaria en la concepción y gestación de un hijo: su discurso apunta fundamentalmente al deseo, ese deseo como potencia transformadora, que hace de ese embrión, que puede ser alojado en el útero o congelado, en espera, propio o ajeno, lo transforma en un hijo esperado.

La diferencia entre quedar embaraza y el ser madre comporta una apuesta pascaliana. Así como Pascal "apostó a la existencia del Otro, ella también hace una apuesta inconsciente, que el objeto que lleva en su vientre será sujeto. Es precisamente este juicio inconsciente (esta bejabung primordial que al mismo tiempo que afirma, niega su condición de viviente puro, de puro organismo) el que le permite hablarle largamente, y tomar como respuesta lingüística sus manifestaciones corporales" (Yankelevich, 1998, p.65, el agregado es mío).

A mi entender en el discurso de nuestra diputada asistimos a la incidencia política del psicoanálisis, en nuestros representantes, actores responsables de pensar las leyes que comandan nuestra vida anclada en la civilización que nos aloja. Incidencia política que pone en primer plano justamente otra concepción de cuerpo, que no es exclusivamente el cuerpo biológico sino el que lleva en su seno el deseo como condición humana de la reproducción de nuestra especie. Es la dimensión del inconsciente engarzada al cuerpo, permitiendo la descompletud de los discursos totalizantes, dimensión que tiene plena vigencia a la hora de poner en juego la diferencia entre un embarazo deseado y otro que no lo es.

Lo que finalmente quiero plantear es que la posibilidad de dar lugar en nuestra 
sociedad a la opción de decidir comandada por esa posición deseante implica hacerle lugar a aquello que no se deja capturar por el determinismo biologicista que intenta borrar la huella singular de cada uno.

Lo más importante es asumir socialmente que esas elecciones de hecho se producen; están dadas desde hace muchísimos años en la práctica del aborto, pero asumirlo en el seno de la sociedad implica que esa decisión no ponga en juego necesariamente la apuesta más cara que es el riesgo de vida, que no se mueran miles de mujeres por realizar esa práctica en la clandestinidad al no ser incluido dentro de las políticas de salud y como un derecho.

\section{REFERENCIAS BiBLIOGRÁFICAS}

Assoun, P-L (2013) El cuerpo entre clínca y metapsicológia: El efecto plástico inconsciente. En Analizando el cuerpo (pp.29-59). Barcelona. España. S\&D Editores.

Barthes, R (1978) Fragmentos de un discurso amoroso. Buenos Aires, Argentina. Siglo veintiuno editores

Chapuis, J (2013) La adecuación del cuerpo sexuado. En Analizando el cuerpo. (pp.129-147). Barcelona. España. S \& D Editores.

Cerruti, G (13-06-18). Youtube. Recuperado en https://www.youtube.com/ watch? $\mathrm{v}=1 \mathrm{AcXDGegMwM}$

Cevasco, R (2010) La discordancia de los sexos. Barcelona. España. S\&D Editores

Freud, S (1915). Lo inconsciente en Vol XIV, Obras Completas, Buenos Aires, Argentina. Amorrortu Editores.

(1893) Algunas consideraciones con miras a un estudio comparativo de las parálisis motrices orgánicas e histéricas en Vol I, Obras completas Buenos Aires, Argentina. Amorrortu Editores. (1923) El yo el Ello en Vol XIX, Obras completas, Buenos Aires, Argentina. Amorrortu Editore

Foucault, M (1978-1979) Nacimiento de la Biopólitica. Buenos Aires, Argentina. Fondo de Cultura Económica Editores 
Groddeck, G (1977) Carta de Freud a Groddeck, del 5 de Junio de 1917, en Groddeck, George Ça et moi (pp.44). Paris. Francia. Gallimard Editores

LaCAN, J (1971) Radiofonia y televisión. Buenos Aires, Argentina. Editorial Anagrama.

(1971-1972) Ou Pire, Seminario XIX, clase 1. Buenos Aires, Argentina. Editorial Paidos.

(2001) “Joyce el síntoma”, en Otros Escritos, Buenos Aires, Argentina. Editorial Paidos

(1967-1968) El objeto en psicoanálisis,inédito

Mazzuca, R (2003). Perversion, De la psychopathia sexualis a la subjetividad perversa. Buenos Aires. Argentina. Berggasse Editores

YANKELEVICH, H (1998). Ensayos sobre autismo y psicosis. Buenos Aires. Argentina. Letra Viva Editores
RESEÑA CURRICULAR DEL AUTOR:

Silvina Garo es psicoanalista. Magister en Psicoanálisis, UNR. Profesora Adjunta de la Cátedra Psicoanálisis y psicopatología. Actualmente Directora del Departamento de Psicoanálisis de la Facultad de Psicología, UNR. Ha publicado su primer libro Navegar es preciso. Una travesía por la clínica freudiana a través del duelo (Homo Sapiens; 2015) y numerosos artículos en diversas revistas y libros de interés científico. 